\title{
BIBLIOGRAFIJA RADOVA OBJAVLJENIH U ČASOPISU STUDIA ETHNOLOGICA CROATICA OD 2006. DO 2017. GODINE
}

\author{
DOI: $10.17234 /$ SEC.30.12
}

\author{
Priredila Inja Cahun
}





\section{NAPOMENA PRIREĐIVAČA}

U povodu objave jubilarnog 30. broja časopisa Studia ethnologica Croatica, uredništvo je odlučilo objaviti bibliografiju radova objavljenih u časopisu od 2006. do 2017. godine. Time se nastavlja kontinuitet izrade bibliografija časopisa koji je započet radom "Izdavaštvo Odsjeka za etnologiju i kulturnu antropologiju" autorice Marijane Belaj (Belaj 2006). Sastavni dio toga rada jest bibliografija časopisa Studia ethnologica Croatica za razdoblje od 1989. godine, kada je objavljen prvi broj časopisa, do 2005. godine. Obje bibliografije zajedno daju pregled radova objavljenih u časopisu od početka izlaženja 1989. do posljednjega objavljenog broja u 2017. godini.

Niže popisani radovi poredani su kronološki, i to grupiranjem prema svesku u kojem su objavljeni (dakle, od sveska 18 iz 2006. godine do sveska 29. iz 2017. godine). Unutar svakog sveska radovi su podijeljeni prema kategorizaciji članaka koja se koristi u časopisu, a unutar tih kategorija popisani su abecedno prema prezimenu prvog autora. Kategorije članaka su sljedeće: izvorni znanstveni rad, prethodno priopćenje, pregledni rad, stručni rad i prikazi aktualnih izdanja i događaja. U obrađenih 11 svezaka objavljeno je ukupno 248 radova, a, prema kategorizaciji, riječ je o 99 izvornih znanstvenih članaka, 20 prethodnih priopćenja, 16 preglednih radova, 4 stručna rada i 79 prikaza. Trideset radova kategoriziranih kao Ostalo odnosi se na 15 radova o povijesti i aktivnostima Odsjeka za etnologiju i kulturnu antropologiju Filozofskog fakulteta Sveučilišta u Zagrebu, 12 izvještaja o znanstvenim projektima Odsjeka, 1 In memoriam, 1 dodatak članku i 1 bibliografija. Uvodnici urednika nisu uključeni u bibliografiju radova. Unutar obrađenog razdoblja izmijenila su se tri glavna urednika. Prof. dr. sc. Vitomir Belaj obnašao je dužnost glavnog urednika do broja 25 (2013) kada tu funkciju preuzima dr. sc. Marijana Belaj, a od broja 28 (2016) do danas glavna je urednica dr. sc. Tihana Rubić.

Pojedini svesci časopisa, objavljeni unutar obrađenog razdoblja, svojim su sadržajem posvećeni određenim temama odnosno događajima. Svezak 18 (2006) posvećen je 80. jubileju neprekinute nastave Odsjeka za etnologiju i kulturnu antropologiju. Stoga prvi dio toga broja obrađuje povijest Odsjeka, opisuje ostvarene suradnje, projekte, istraživanja i elemente studijskog procesa, a drugi dio broja, uobičajeno, donosi nekoliko izvornih znanstvenih članaka proteklih istraživanja. Uredništvo je svezak 19 (2007) posvetilo prof. dr. sc. Vitomiru Belaju za njegov rođendan i dugogodišnji rad. Skup Novi kurikulumi studija etnologije i kulturne antropologije - uz obljetnicu 80 godina hrvatske etnologije održan je 2007. godine, a radovi s toga skupa objavljeni su u svesku 20 (2008). 
Svezak 21 (2009) podijeljen je u dva dijela: prvi dio donosi radove sa skupa Pag u praskozorje hrvatskoga kršćanstva održanog 2008. godine, a drugi dio radove šire etnološke tematike. Radovi polaznika poslijediplomskoga doktorskog studija koji su nastali u okviru kolegija Etnografije putovanja: transnacionalne prakse migranata i izloženi su na istoimenom znanstvenom skupu 2009. godine, objavljeni su u prvom dijelu sveska 22 (2010), a u drugom dijelu objavljena su recentna istraživanja domaćih i inozemnih znanstvenika iz drugih aktualnih etnoloških i kulturnoantropoloških tema. Tematski blok na engleskom jeziku pod naslovom Traditional knowledge as the key for sustainable rural development. Utopia or reality? bavi se razvojem ruralnog prostora u suvremenom kontekstu i prvi je dio sveska 28 (2016), a drugi dio donosi znanstvene i stručne radove raznih tematika, kao i prikaze novih izdanja i proteklih događanja. Svezak 29 (2017) podijeljen je na više cjelina. Prvi dio broja čini tematski blok na engleskom jeziku unutar kojeg su objavljeni radovi s međunarodnog simpozija Socijalistički spomenici $i$ modernizam i dva pozvana rada, zatim slijede znanstveni radovi raznih etnoloških i kulturnoantropoloških tema, treći je dio posvećen 90. obljetnici redovitog održavanja nastave na Odsjeku za etnologiju i kulturnu antropologiju u sklopu kojeg se nalaze izvještaji o znanstvenim projektima Odsjeka i bibliografija radova djelatnika Odsjeka objavljenih od 2006. do 2016. godine (Majer 2017), a posljednji dio sveska sadrži prikaze knjiga i događaja.

Način citiranja članaka u časopisu koji je preporučen u časopisu Studia ethnologica Croatica, uz manje izmjene, korišten je i pri izradi ove bibliografije. Strukturu bibliografske jedinice čine ime i prezime autora, godina, naslov rada, naslov časopisa, oznaka sveska i broja, početna i završna stranica rada i poveznica na mrežnu inačicu rada. Izmjene u odnosu na preporučenu strukturu referencija odnose se na navođenje usporednih naslova, i to u dva slučaja. Prvi slučaj odnosi se na naslov prijevoda rada, a on je naveden iza originalnog naslova i odvojen je kosom crtom (/); u zagradama je opaskom istaknuto da je riječ o prijevodu, a opaska je napisana na jeziku prijevoda. Zatim, ako je naslov rada preveden uz sažetak, i on je naveden, ali je odvojen znakom jednakosti (=); u zagradama je opaska da je riječ o sažetku na jeziku sažetka.

\section{LITERATURA:}

BELAJ, Marijana. 2006. "Izdavaštvo Odsjeka za etnologiju i kulturnu antropologiju”. Studia ethnologica Croatica, vol. 18:71-94. https:// hrcak.srce.hr/17522

MAJER, Ivana. "Bibliografija Odsjeka za etnologiju i kulturnu antropologiju Filozofskog fakulteta Sveučilišta u Zagrebu (2006. 2016.)". Studia ethnologica Croatica, vol. 29:411-496. https:// hrcak.srce.hr/191709 


\section{Svezak 18 (2006)}

\section{Izvorni znanstveni članak}

BELAJ, Vitomir i Goran PAVEL ŠANTEK. 2006. "Paški sveti trokut" = "The Holy Triangle of Pag" [Summary]. Studia ethnologica Croatica, vol. 18:153-183. https://hrcak.srce.hr/17529

RAJKOVIĆ, Marijeta i Jasmina JURKOVIĆ. 2006. "Primorski Bunjevci Krivopućani na području Virovitice (studija slučaja unutarnje migracije)" = "Bunjevci Krivopućani from Primorje in the area of Virovitica (Case study of inner migration)" [Summary]. Studia ethnologica Croatica, vol. 18:231-280. https://hrcak.srce.hr/17531

SVIRAC, Manda. 2006. "Aleksandar Gahs - Drugi Požežanin" = “Aleksandar Gahs - D’un Deuxième Požežanin” [Summary]. Studia ethnologica Croatica, vol. 18:299-311. https://hrcak.srce.hr/17533

ŠKRBIĆ Alempijević, Nevena. 2006. “Tko uopće želi biti živi karnavol? Tonči Kukoč Bager kao nositelj mjesne karnevalesknosti" = "Who Would Even Want to Be a Living Karnavol? Tonči Kukoč Bager as the Carrier of the Local Carnivalesquesness" [Summary]. Studia ethnologica Croatica, vol. 18:185-229. https://hrcak.srce.hr/17530

VOJNOVIĆ TRAŽIVUK, Branka. 2006. “'Dalmatinska narodna umjetnost' u Austro-Ugarskoj Monarhiji početkom 20. stoljeća" $=$ "'Dalmatian Folk Art' in Austro-Hungarian Monarchy at the Beginning of the 20th Century" [Summary]. Studia ethnologica Croatica, vol. 18:281-298. https://hrcak.srce.hr/17532 


\section{Ostalo}

BELAJ, Marijana. 2006. "Izdavaštvo Odsjeka za etnologiju i kulturnu antropologiju". Studia ethnologica Croatica, vol. 18:71-94. https://hrcak.srce.hr/17522

BELAJ, Vitomir. 2006. "Novi program poslijediplomskoga doktorskog studija na Odsjeku za etnologiju i kulturnu antropologiju". Studia ethnologica Croatica, vol. 18:21-28. https://hrcak.srce.hr/17515

BUKOVČAN, Tanja i Sanja POTKONJAK. 2006. "Vodič kroz CEEPUS za studente ili kako je Iva otišla u Prag". Studia ethnologica Croatica, vol. 18:43-47. https://hrcak.srce.hr/17518

ČERNELIĆ, Milana. 2006. "Projekt 'Identitet i etnogeneza primorskih Bunjevaca'". Studia ethnologica Croatica, vol. 18:49-56. https://hrcak.srce.hr/17519

ĐAKOVIĆ, Branko. 2006. "Etnološka kartografija". Studia ethnologica Croatica, vol. 18:65-70. https://hrcak.srce.hr/17521

KATUNAR, Ljubica. 2006. "Knjižnica Odsjeka za etnologiju i kulturnu antropologiju". Studia ethnologica Croatica, vol. 18:95-97. https://hrcak.srce.hr/17523

KELEMEN, Petra i Tihana RUBIĆ. 2006. “Arhiv Odsjeka za etnologiju i kulturnu antropologiju". Studia ethnologica Croatica, vol. 18:99-114. https://hrcak.srce.hr/17524

PETROVIĆ LEŠ, Tihana. 2006. "Projekt 'Organizirano kućno rukotvorstvo u 19. i 20. stoljeću u Hrvatskoj”". Studia ethnologica Croatica, vol. 18:57-63. https://hrcak.srce.hr/17520

PLETENAC, Tomislav. 2006. "Između paradigmi: je li Odsjek postao dobro mjesto za krizu?". Studia ethnologica Croatica, vol. 18:920. https://hrcak.srce.hr/17514

RAJKOVIĆ, Marijeta. 2006. "Terenska nastava na studiju etnologije i kulturne antropologije". Studia ethnologica Croatica, vol.

18:123-136. https://hrcak.srce.hr/17526

STIPANČEVIĆ, Mario. 2006. "Ostavština Milovana Gavazzija u Hrvatskom državnom arhivu". Studia ethnologica Croatica, vol. 18:115-121. https://hrcak.srce.hr/17525 
SVIRAC, Manda. 2006. "Međunarodna suradnja s etnolozima Jagelonskog sveučilišta u Krakovu”. Studia ethnologica Croatica, vol. 18:35-42. https://hrcak.srce.hr/17517

ŠKRBIĆ ALEMPIJEVIĆ, Nevena. 2006. "Suradnja Odsjeka za etnologiju i kulturnu antropologiju Filozofskog fakulteta Sveučilišta u Zagrebu s Odsjekom za kulturalne studije i povijest umjetnosti Filozofskog fakulteta Sveučilišta u Bergenu, Norveška". Studia ethnologica Croatica, vol. 18:29-34. https://hrcak.srce.hr/17516

VINCE PALLUA, Jelka. 2006. "Mediteranistika - novina u kurikulumu studija etnologije i kulturne antropologije". Studia ethnologica Croatica, vol. 18:147-150. https://hrcak.srce.hr/17528

VINŠĆAK, Tomo. 2006. "Izvaneuropska istraživanja na Odsjeku za etnologiju i kulturnu antropologiju od 1993. do 2006. godine”. Studia ethnologica Croatica, vol. 18:137-145. https://hrcak.srce. $\mathrm{hr} / 17527$

\section{Svezak 19 (2007)}

\section{Izvorni znanstveni članak}

BELAJ, Marijana. 2007. "Sveci zaštitnici u pobožnosti zajednice: studija o Krivome Putu kod Senja" = "Patron Saints in Community Religiosity: A Case Study from the Croatian Village of Krivi Put" [Summary]. Studia ethnologica Croatica, vol. 19:47-76. https://hrcak.srce.hr/22112

BERMANEC, Krešimir, Mario KATIĆ, Tomislav OROZ i Nevena ŠKRBIĆ ALEMPIJEVIĆ. 2007. "Sjećanje na Viški boj: proslave, spomenici, naracije" = "Memory of the Battle of Vis: Festivals, Monuments, Narratives" [Summary]. Studia ethnologica Croatica, vol. 19:77-127. https://hrcak.srce.hr/22113

ČERNELIĆ, Milana. 2007. "Prilog poznavanju kulturnopovijesne metode u hrvatskoj etnologiji i raspravi o njoj" = "Contribution to Understanding and Discussion of Cultural-Historical Method in Croatian Ethnology" [Summary]. Studia ethnologica Croatica, vol. 19:5-16. https://hrcak.srce.hr/22110 
ČERNELIĆ, Milana i Marijeta RAJKOVIĆ. 2007. "Mogućnosti revitalizacije tradicijske baštine na području Krivoga Puta u senjskome zaleđu" = "Possibilities of Revitalization of Traditional Heritage in the Region of Krivi Put near the Town of Senj" [Summary]. Studia ethnologica Croatica, vol. 19:245-268. https://hrcak.srce.hr/22136

FJELL, Lennart. 2007. "Contemporary Festival: Polyphony of Voices And Some New Agents" = "Suvremeni festivali: polifonija glasova i neki novi čimbenici" [Sažetak]. Studia ethnologica Croatica, vol. 19:129-149. https://hrcak.srce.hr/22130

JELINČIĆ, Daniela Angelina. 2007. “Agroturizam u europskom kontekstu" = "Agrotourism in European Context" [Summary]. Studia ethnologica Croatica, vol. 19:269-291. https://hrcak.srce.hr/22137

LEBOŠ, Sonja. 2007. “Analiza putopisa 'Sjećanje na putovanje u zemlju Slavena s juga' (Recuerdos de un viaje al pas de los Eslavos del Sur) autora Georgesa Perrota" = "Analysis of the "Travelogue Records of the Travel to the Land of Slavs from the South' (Recuerdos de un viaje al país de los Eslavos del Sur) by Georges Perrot" [Summary]. Studia ethnologica Croatica, vol. 19:151-170. https://hrcak.srce. $\mathrm{hr} / 22132$

POTKONJAK, Sanja i Tomislav PLETENAC. 2007. "Grad i ideologija: 'kultura zaborava' na primjeru grada Siska" = "City and Ideology: 'Cultures of Oblivion' on the Example of the Town of Sisak" [Summary]. Studia ethnologica Croatica, vol. 19:171-198. https://hrcak.srce.hr/22133

ŠKRBIĆ ALEMPIJEVIĆ, Nevena. 2007. "Predstavljanje svadbe u hrvatskim pokladnim običajima" = "Wedding Presentations in Croatian Carnival Customs" [Summary]. Studia ethnologica Croatica, vol. 19:199-222. https://hrcak.srce.hr/22134

VINCE, Jelka. 2007. "Endemsko prema etnokartografskom: nova razmišljanja na marginama etnoloških karata (primjer virdžina, zavjetovanih djevojaka)" = "Endemic opposed to ethnocartographic: new reflections on the margins of ethnological maps (the case of virgins, girls offered by a vow)" [Summary]. Studia ethnologica Croatica, vol. 19:17-45. https://hrcak.srce.hr/22111 
VUKUŠIĆ, Ana-Marija. 2007. “Zapisi o Sinjskoj alki i njihova primjenjivost u etnološkome istraživanju" = "Notes on the Sinjska Alka and their Applicability in Ethnological Research" [Summary]. Studia ethnologica Croatica, vol. 19:223-243. https://hrcak.srce. $\mathrm{hr} / 22135$

\section{Pregledni rad}

TVEIT, Eva-Marie. 2007. "Folklore on Display: the Authenticity Debate Revisited" = "Folklor u prikazima: još malo o autentičnosti" [Sažetak]. Studia ethnologica Croatica, vol. 19:293-302. https://hrcak.srce.hr/22138

\section{Svezak 20 (2008)}

\section{Izvorni znanstveni članak}

MUR ŠI $\check{C}$, Rajko. 2008. "Forefathers and Successors at the Department of Ethnology and Cultural Anthropology, University Of Ljubljana: Paths in the Development of Slovene Ethnology/Cultural Anthropology" = "Osnivači i sljedbenici na Odsjeku za etnologiju i kulturnu antropologiju Sveučilišta u Ljubljani: putovi i stranputice u razvoju slovenske etnologije / kulturne antropologije (Sažetak)". Studia ethnologica Croatica, vol. 20:107-125. https://hrcak.srce.hr/29449

OBAD, Orlanda. 2008. "The European Union from the Postcolonial Perspective: Can the Periphery ever Approach the Center?" / "Europska unija promotrena iz postkolonijalne perspektive: može li periferija ikada pristupiti središtu? (Prijevod članka)". Studia ethnologica Croatica, vol. 20:9-35. https://hrcak.srce.hr/29443

POTKONJAK, Sanja, Damir ARSENIJEVIĆ, Ajla DEMIRAGIĆ i Jelena PETROVIĆ. 2008. "Između politike pokreta i politike znanja feminizam i ženski/rodni studiji u Hrvatskoj, Bosni i Hercegovini i Sloveniji" = "Inbetween the Politics of Movement and the Politics of Knowledge - Feminism and Women's/Gender Studies in Croatia, Bosnia and Hercegovina, and Slovenia (Summary)". Studia ethnologica Croatica, vol. 20:57-96. https://hrcak.srce.hr/29457 


\section{Prethodno priopćenje}

ÅGOTNES, Hans-Jakob. 2008. "Cultural Studies in a Changing World. 2008. 'Kulturvitenskap' in Bergen in its Social and Intellectual Contexts" = "Kulturni studiji u svijetu promjena. 'Kulturvitenskap' u Bergenu i njihov društveni i intelektualni kontekst (Sažetak)". Studia ethnologica Croatica, vol. 20:223-243. https://hrcak.srce. $\mathrm{hr} / 29456$

\section{Pregledni rad}

BAĆEVIĆ, Jana. 2008. "Anthropological Educational Policy in the Light of European Transformations" = "Antropološka obrazovna politika u svjetlu europske transformacije (Sažetak)". Studia ethnologica Croatica, vol. 20:37-55. https://hrcak.srce.hr/29446

BARANSKI, Janusz. 2008. "New Polish Anthropology" = "Nova poljska antropologija (Sažetak)". Studia ethnologica Croatica, vol. 20:211222. https://hrcak.srce.hr/29455

BARNA, Gábor. 2008. “The Szeged School of Ethnology: Traditions, Efforts and Challenges. Approaches to Teaching Ethnology in the Bologna Process" = "Segedska škola etnologije: tradicije, napori i izazovi. Pristupi podučavanju etnologije u sklopu bolonjskog procesa (Sažetak)". Studia ethnologica Croatica, vol. 20:181-192. https://hrcak.srce.hr/29453

TÖHÖTÖM, Szabó Á. 2008. “Anthropological Challenge - Ethnographic Tradition. The Quiet Transition of the Hungarian Ethnography in Romania" = "Antropološki izazovi - etnografska tradicija. Mirna tranzicija mađarske etnografije u Rumunjskoj (Sažetak)". Studia ethnologica Croatica, vol. 20:161-180. https://hrcak.srce.hr/29452

TUŽINSKÁ, Helena. 2008. "How Far Have We Gone with Being Applied? From Nrodopis to Antropolgia, Curricula Heterogeneity and Public Engagement in Slovakia" = "Koliko smo odmakli s biti primijenjen? Od nrodopisa do antropolgie, heterogenost kurikuluma i javno uključivanje u Slovačkoj (Sažetak)". Studia ethnologica Croatica, vol. 20:193-209. https://hrcak.srce.hr/29454 
ŽIKIĆ, Bojan. 2008. "Escape from Ethnos, Tradition in Transition, and the Battle for Anthropology. Restructuring the Curriculum in Belgrade Academia" = "Bijeg od etnosa, tradicije u tranziciji i bitka za antropologiju. Restrukturiranje kurikuluma u beogradskoj Akademiji (Sažetak)". Studia ethnologica Croatica, vol. 20:127147. https://hrcak.srce.hr/29450

\section{Stručni rad}

ČAPO ŽMEGAČ, Jasna i Valentina GULIN ZRNIĆ. 2008. “A Curriculum of Cultural and Social Anthropology: Proposals and Perspectives in Croatia" = "Program kulturne i socijalne antropologije: prijedlozi i perspektive u Hrvatskoj (Sažetak)”. Studia ethnologica Croatica, vol. 20:97-105. https://hrcak.srce.hr/29448

OLTEANU, Antoaneta. 2008. "Teaching Anthropology in Romania" = "Antropologija na sveučilištima u Rumunjskoj (Sažetak)". Studia ethnologica Croatica, vol. 20:149-159. https://hrcak.srce.hr/29451

\section{Svezak 21 (2009)}

\section{Izvorni znanstveni članak}

BABIĆ, Darko i Marijeta RAJKOVIĆ. 2009. "Prilog za razvoj ekomuzeja u Ravnim kotarima" = "Contribution to the Development of EcoMuseum in Ravni Kotari" [Summary]. Studia ethnologica Croatica, vol. 21:307-329. https://hrcak.srce.hr/45124

BELAJ, Juraj. 2009. "Martin-Breg između poganstva i kršćanstva" = "Martin-Breg between Paganism and Christianity" [Summary]. Studia ethnologica Croatica, vol. 21:79-99. https://hrcak.srce. $\mathrm{hr} / 45115$

BELAJ, Vitomir. 2009. "Poganski bogovi i njihovi kršćanski supstituti" = "Pagan Gods and Their Christian Substitutes" [Summary]. Studia ethnologica Croatica, vol. 21:169-197. https://hrcak.srce.hr/45118

BELAJ, Vitomir. 2009. "Postati kršćaninom kao proces. Uvodno izlaganje održano na Sveučilištu u Zadru, na početku znanstvenoga skupa Pag u praskozorje hrvatskoga kršćanstva (Zadar - Pag, 26. - 28. 9. 2008.)" = 
"Becoming Christian as a Process. Introductory Notes to the Scientific Conference Pag at the Dawn of Croatian Christianity Held at the University of Zadar (Zadar - Pag, 26-28.9.2008.)" [Summary]. Studia ethnologica Croatica, vol. 21:9-25. https://hrcak.srce.hr/45112

DAMJANOVIĆ, Dragan. 2009. "Narodni motivi u projektima Friedricha Schmidta za Hrvatsku" = "Folk Motifs in Friedrich Schmidt's Projects in Croatia" [Summary]. Studia ethnologica Croatica, vol. 21:331-354. https://hrcak.srce.hr/45125

GOSS, Vladimir P. 2009. "Landscape as History, Myth, and Art. An Art Historian's View" = "Krajolik kao povijest, mit i umjetnost. Pogled jednog povjesničara umjetnosti” [Sažetak]. Studia ethnologica Croatica, vol. 21:133-168. https://hrcak.srce.hr/45117

HAMERŠAK, Marijana. 2009. "Usmenost za djecu u hrvatskoj etnologiji i folkloristici" = "Orality for Children in Croatian Ethnology and Folkloristics" [Summary]. Studia ethnologica Croatica, vol. 21:233-254. https://hrcak.srce.hr/45121

HOLZER, Georg. 2009. "Koledanje i njegovi poganski elementi u Novom Selu i drugim gradišćanskohrvatskim selima" = "Das Koledanje und Seine Heidnischen Elemente in Neudorf und Anderen Burgenlandkroatischen Dörfern" [Zusammenfassung]. Studia ethnologica Croatica, vol. 21:101-131. https://hrcak.srce.hr/45116

PLETENAC, Tomislav. 2009. “Živjeti u realnom. Neke posljedice primjene teorijske psihoanalize na konstrukciju objekta i subjekta kulturne analitike" = "Living in Real. Some Consequences of Applying Theoretical Psychoanalysis on Construction of Object and Subject of Cultural Analysis" [Summary]. Studia ethnologica Croatica, vol. 21:199-217. https://hrcak.srce.hr/45119

PLETERSKI, Andrej. 2009. "Nekateri topografski vidiki obrednih mest" $=$ "Some Topographic Aspects of Ritual Places" [Summary]. Studia ethnologica Croatica, vol. 21:27-46. https://hrcak.srce.hr/45113

ŠANTEK, Goran Pavel. 2009. "Paški sveti prostor. Prilog tumačenju" $=$ "Island of Pag's Sacred Space. Contribution to Interpretation" [Summary]. Studia ethnologica Croatica, vol. 21:47-77. https://hrcak.srce.hr/45114 


\section{Prethodno priopćenje}

BELAJ, Melanija. 2009. "Obiteljski fotografski album" = "Family Photo Album" [Summary]. Studia ethnologica Croatica, vol. 21:285305. https://hrcak.srce.hr/45123

FIKFAK, Jurij. 2009. "Simboli in ritualne prakse spora in sožitja. Nekateri italijansko-slovenski diskurzi" = "Symbols and Ritual Practices of Conflict and Coexistence. Some Italian-Slovenian Discourses" [Summary]. Studia ethnologica Croatica, vol. 21:355387. https://hrcak.srce.hr/45126

\section{Pregledni rad}

MARKOVIĆ, Jelena. 2009. "Dječja usmenost i usmenost o djetinjstvu u hrvatskoj etnologiji i folkloristici" = "Children's Orality and Orality on Childhood in Croatian Ethnology and Folkloristics" [Summary]. Studia ethnologica Croatica, vol. 21:255-284. https://hrcak.srce. $\mathrm{hr} / 45122$

ŠKOVIEROVÁ, Zita. 2009. "Current Problems of Social Culture and Ethnology in Slovakia" = "Živjeti u realnom. Neke posljedice primjene teorijske psihoanalize na konstrukciju objekta i subjekta kulturne analitike". Studia ethnologica Croatica, vol. 21:219-231. https://hrcak.srce.hr/45120

\section{Svezak 22 (2010)}

\section{Izvorni znanstveni članak}

BELAJ, Marijana i Sandra UREM. 2010. "Pirovačke kapelice i poklonci: mjesta interakcije, sjećanja i identifikacije" = "Wayside Shrines and Chapels of Pirovac: Places of Interaction, Memory and Identification" [Summary]. Studia ethnologica Croatica, vol. 22:255-282. https://hrcak.srce.hr/62254

BITI, Ozren. 2010. "Sportski objekti kao objekti prijepora: gdje sve i kako trošimo (na) sport" = "Sports Objects as Objects of Dispute: Where and How We Spend (on) Sports" [Summary]. Studia ethnologica Croatica, vol. 22:237-253. https://hrcak.srce.hr/62251 
BUKOVČAN, Tanja. 2010. "Medicina u kandžama etnologije: mala regionalna povijest transformacije tradicijske medicine u medicinsku antropologiju" = "How Ethnology (Mis)Treated Medicine: Little Regional History of Transformation of Traditional Medicine into Medical Anthropology" [Summary]. Studia ethnologica Croatica, vol. 22:215-235. https://hrcak.srce.hr/62250

ČAPO ŽMEGAČ, Jasna. 2010. "Različiti pristupi povratnim migracijama: primjer Hrvatske" = "Different Approaches to Return Migration: the Case of Croatia" [Summary]. Studia ethnologica Croatica, vol. 22:11-38. https://hrcak.srce.hr/62238

ČERNELIĆ, Milana i MARIJETA RAJKOVIĆ Iveta. 2010. “Ogled o primorskim Bunjevcima: povijesna perspektiva i identifikacijski procesi" = "Review on Coastal Bunjevci: Historical Perspective and the Processes of Identification" [Summary]. Studia ethnologica Croatica, vol. 22:283-316. https://hrcak.srce.hr/62255

FRANGEŠ, Grga. 2010. “Transhumancija - transnacionalizam: šarplaninski ovčari na Učki" = "Transhumation as Transnationalism: Sheep Herders from Šar-Planina on Učka Mountain” [Summary]. Studia ethnologica Croatica, vol. 22:139-163. https://hrcak.srce. $\mathrm{hr} / 62245$

JERNEJ, Mirna. 2010. "Obiteljski transnacionalni prostor: studija slučaja" = "Transnational Space of a Family: a Case Study" [Summary]. Studia ethnologica Croatica, vol. 22:61-83. https://hrcak.srce.hr/62241

LIPOVEC ČEBRON, Uršula. 2010. "The Construction of a Health Uninsurant: People without Medical Citizenship as Seen by Some Slovene Health Workers" = "Predodžbe o neosiguranicima: ljudi bez medicinskog državljanstva promatrani od strane slovenskih zdravstvenih radnika" [Sažetak]. Studia ethnologica Croatica, vol. 22:187-212. https://hrcak.srce.hr/62249

MATOŠEVIĆ, Andrea. 2010. "Pronađeno u prijevozu: studentske prakse i iskustva u autobusu između Pule i Padove" = "Found in Transportation: Students' Practices and Experiences on the Coach Line between Pula and Padova" [Summary]. Studia ethnologica Croatica, vol. 22:115-137. https://hrcak.srce.hr/62243 
MIHALJEVIĆ, Lucija. 2010. "Transnacionalne prakse žena u diplomaciji” $=$ "Women in Diplomacy: Their Private Transnational Practices" [Summary]. Studia ethnologica Croatica, vol. 22:85114. https://hrcak.srce.hr/62242

MOUNTCASTLE, Amy. 2010. "Safeguarding Intangible Cultural Heritage and the Inevitability of Loss: a Tibetan Example" = "Čuvanje nematerijalne kulturne baštine i neizostavnost gubitka: primjer Tibeta" [Sažetak]. Studia ethnologica Croatica, vol. 22:339-359. https://hrcak.srce.hr/62257

POVRZANOVIĆ FRYKMAN, Maja. 2010. "Materijalne prakse bivanja i pripadanja u transnacionalnim društvenim prostorima" = "Material Practices of Being and Belonging in Transnational Social Fields" [Summary]. Studia ethnologica Croatica, vol. 22:39-60. https://hrcak.srce.hr/62239

REPIČ, Jaka. 2010. "Migration, Informal Economy and Social Exclusion in Spain" = "Migracije, siva ekonomija i društveno isključivanje u Španjolskoj" [Sažetak]. Studia ethnologica Croatica, vol. 22:165186. https://hrcak.srce.hr/62248

ŠKRBIĆ ALEMPIJEVIĆ, Nevena i Rebeka ŽABČIĆ MESARIĆ. 2010. "Croatian Coastal Festivals and the Construction of the Mediterranean" = "Hrvatski priobalni festivali i konstruiranje Sredozemlja" [Sažetak]. Studia ethnologica Croatica, vol. 22:317337. https://hrcak.srce.hr/62256

\section{Prethodno priopćenje}

KLAUS, Simona. 2010. "Heroes in Virtual Space" = "Heroji virtualnog svijeta" [Sažetak]. Studia ethnologica Croatica, vol. 22:361-391. https://hrcak.srce.hr/62258

\section{Recenzija, Prikaz}

AGIČIĆ, Damir. 2010. “Tihana Rubić, Nevena Škrbić-Alempijević, Željka Jelavić i Željka Petrović Osmak, ur.: 50 godina Hrvatskoga etnološkog društva (1959. - 2009.)". Studia ethnologica Croatica, vol. 22:409-412. https://hrcak.srce.hr/62263 
GRGURINOVIĆ, Ivona. 2010. "Julia Kuehn i Paul Smethurst, ur.: Travel Writing, Form and Empire. The Poetics and Politics of Mobility". Studia ethnologica Croatica, vol. 22:412-415. https://hrcak.srce. $\mathrm{hr} / 62264$

GRGURINOVIĆ, Ivona. 2010. "Magdalena Nowicka i Maria Rovisco, ur.: Cosmopolitanism in Practice". Studia ethnologica Croatica, vol. 22:416-418. https://hrcak.srce.hr/62265

KELEMEN, Petra i Sanja LONČAR. 2010. "Tihana Petrović Leš, ur.: Etnolog Vitomir Belaj. Zbornik radova povodom 70. rođendana Vitomira Belaja". Studia ethnologica Croatica, vol. 22:402-405. https://hrcak.srce.hr/62261

KOMAR, Tibor. 2010. "Radoslav Katičić: Božanski boj-tragovima svetih pjesama naše pretkršćanske starine". Studia ethnologica Croatica, vol. 22:399-402. https://hrcak.srce.hr/62260

VINCE PALLUA, Jelka. 2010. "Milana Černelić, Marijeta Rajković i Tihana Rubić, ur.: Živjeti na Krivom Putu. Etnološka monografija o primorskim Bunjevcima". Studia ethnologica Croatica, vol. 22:406-408. https://hrcak.srce.hr/62262

\section{Svezak 23 (2011)}

\section{Izvorni znanstveni članak}

BOŽIĆ-VRBANČIĆ, Senka i Mario VRBANČIĆ. 2011. "Captain Euro: Time, Space and Imperial Power" = "Captain Euro: vrijeme, prostor i imperijalna moć" [Sažetak]. Studia ethnologica Croatica, vol. 23:25-46. https://hrcak.srce.hr/74740

ČARGONJA, Hrvoje. 2011. “A Contribution to Understanding Experience as Discourse" = "Dvosmisleno iskustvo: prilog razumijevanju iskustva kao diskursa" [Sažetak]. Studia ethnologica Croatica, vol. 23:283-308. https://hrcak.srce.hr/74750

HABINC, Mateja. 2011. "Community Building through Festivities: A Case of Dirty Togetherness?" = "Stvaranje zajednica tijekom praznika: primjer prljavog zajedništva" [Sažetak]. Studia ethnologica Croatica, vol. 23:239-258. https://hrcak.srce.hr/74748 
KELEMEN, Petra i Sanja LONČAR. 2011. “'Obično' vs. 'atraktivno': kako priče o načinu života postaju dio turističke ponude" = “"Ordinary' vs. 'Attractive': How Stories on the Way of Life Become a Part of Tourist Offer" [Summary]. Studia ethnologica Croatica, vol. 23:183-214. https://hrcak.srce.hr/74746

KIKA ̌́, Mario, Bojan MUCKO, Jelka VUKOBRATOVIĆ i Petra KELEMEN. 2011. "Urbanoumjetnički festivali: kulturne politike i potencijali subverzivnosti" = "Urban Art Festivals: Cultural Politics and Potentials of Subversity" [Summary]. Studia ethnologica Croatica, vol. 23:67-92. https://hrcak.srce.hr/74742

LEČEK, Suzana i Tihana PETROVIĆ LEŠ. 2011. "Država i znanost:

jugoslavenstvo na III. Slavenskom kongresu geografa i etnografa 1930. godine" = "State and Science: Yugoslav Iden-tity on the Third Slavic Congress of Geographers and Ethnolo-gists in 1930" [Summary]. Studia ethnologica Croatica, vol. 23:149-182. https:// hrcak.srce.hr/74745

LIPOVEC ČEBRON, Uršula. 2011. "“It Hits Your Nerves and All Kinds of Hell Break Loose'. Psychological Distress of the Erased of Slovenia” = "'Pogodi ti živce i pakao se otvori'. Psihičke tegobe izbrisanih u Sloveniji” [Sažetak]. Studia ethnologica Croatica, vol. 23:259-282. https://hrcak.srce.hr/74749

PETROVIĆ, Duško. 2011. “Analiza političkih aspekata studentske blokade Filozofskoga fakulteta u Zagrebu: metoda i strategija studentske blokade" = "Analysis of Political Aspects of Student Blockade at Faculty of Humanities and Social Sciences in Zagreb: Methods and Strategies of Student Blockade" [Summary]. Studia ethnologica Croatica, vol. 23:327-347. https://hrcak.srce.hr/74752

PERINIĆ LEWIS, Ana. 2011. "Hvarski kampanilizam - stereotipi i podrugljivi etnici otoka Hvara" = "Hvar's Campanilism - Stereotypes and Collective Nicknames on the Island of Hvar" [Summary]. Studia ethnologica Croatica, vol. 23:215-237. https://hrcak.srce.hr/74747

POTKONJAK, Sanja i Tomislav PLETENAC. 2011. “Kada spomenici ožive - 'umjetnost sjećanja' u javnom prostoru" = "When Monuments Get Alive - The 'Art of Rememberance' in Public Space” [Summary]. 
Studia ethnologica Croatica, vol. 23:7-24. https://hrcak.srce. $\mathrm{hr} / 74739$

VINŠĆAK, Tomo. 2011. "Tibetska religija Bön" = "Tibetan Religion of Bön" [Summary]. Studia ethnologica Croatica, vol. 23:309326. https://hrcak.srce.hr/74751

VRBANČIĆ, Mario. 2011. “Izbavljenje slike': politička teologija filma” = "Rescued Images': Political Theology of Film" [Summary]. Studia ethnologica Croatica, vol. 23:47-66. https://hrcak.srce.hr/74741

\section{Prethodno priopćenje}

TURK NISKAČ, Barbara. 2011. "Some Thoughts on Ethnographic Fieldwork and Photography" = "Neka razmišljanja o etnografskom terenu i fotografiji” [Sažetak]. Studia ethnologica Croatica, vol. 23:125-148. https://hrcak.srce.hr/74744

\section{Pregledni rad}

MARJANIĆ, Suzana. 2011. "Izvedba političke kuhinje ili performansi u kojima se hrana rabi kao politički stav" = "Political Kitchen Performance or Performance Arts in which Food is Used to Demonstrate a Political Stance" [Summary]. Studia ethnologica Croatica, vol. 23:93-123. https://hrcak.srce.hr/74743

\section{Recenzija, Prikaz}

BASKAR, Bojan. 2011. "Jasna Čapo and Valentina Gulin Zrnić, eds.: Mjesto, nemjesto: Interdisciplinarna promišljanja prostora i kulture". Studia ethnologica Croatica, vol. 23:365-368. https://hrcak.srce. $\mathrm{hr} / 74759$

GRBIĆ, Jadranka. 2011. "Milana Černelić i Marijeta Rajković Iveta, ur.: Zapisi iz gornjih Ravnih kotara: Etnološki, povijesni i muzeološki prilozi o Islamu Latinskom, Islamu Grčkom, Kašiću i Podgradini”. Studia ethnologica Croatica, vol. 23:368-371. https://hrcak.srce. $\mathrm{hr} / 74760$ 
GRGURINOVIĆ, Ivona. 2011. "David Graeber: Direct Action. An Ethnography". Studia ethnologica Croatica, vol. 23:355-357. https://hrcak.srce.hr/74755

GULIN ZRNIĆ, Valentina. 2011. "Suzana Marjanić i Ines Prica, ur.: Mitski zbornik". Studia ethnologica Croatica, vol. 23:374377. https://hrcak.srce.hr/74762

JELAVIĆ, Željka. 2011. "Kultura i ekonomija. Godišnji skup Hrvatskoga etnološkog društva”. Studia ethnologica Croatica, vol. 23:383-384. https://hrcak.srce.hr/74765

KELEMEN, Petra i Sanja LONČAR. 2011. "People Make Places - ways of feeling the world. Deseti kongres SIEF-a". Studia ethnologica Croatica, vol. 23:388-390. https://hrcak.srce.hr/74768

MARJANIĆ, Suzana. 2011. “Andrej Pleterski i Goran Pavel Šantek, ur.: Mirila: kulturni fenomen”. Studia ethnologica Croatica, vol. 23:380-383. https://hrcak.srce.hr/74764

MARJANIĆ, Suzana. 2011. "Tomo Vinšćak: Tibetski buddhizam i bön”. Studia ethnologica Croatica, vol. 23:362-365. https://hrcak.srce. $\underline{\mathrm{hr} / 74758}$

OROZ, Tomislav i Sandra UREM. 2011. "Re-Thinking Humanities and Social Sciences - The Zone and Zones - Radical Spatiality in Our Times. Druga međunarodna znanstvena konferencija". Studia ethnologica Croatica, vol. 23:386-388. https://hrcak.srce.hr/74767

PETROVIĆ, Duško. 2011. “Goran Pavel Šantek: Anthropos religiosus: antropološko-religijski ogledi”. Studia ethnologica Croatica, vol. 23:360-362. https://hrcak.srce.hr/74757

PETROVIĆ, Duško. 2011. "Southeast European (Post) Modernities. 6. konferencija InASEA-e”. Studia ethnologica Croatica, vol. 23:384-386. https://hrcak.srce.hr/74766

PLETENAC, Tomislav. 2011. “Aleksandar Bošković: Kratak uvod u antropologiju". Studia ethnologica Croatica, vol. 23:351353. https://hrcak.srce.hr/74753

PLETENAC, Tomislav. 2011. “Gayatry Chakravorty Spivak: Nacionalizam i imaginacija i drugi eseji”. Studia ethnologica Croatica, vol.

23:357-360. https://hrcak.srce.hr/74756 
POTKONJAK, Sanja. 2011. "Branko Đaković: Igre oko vatre. Prilog etnološkim istraživanjima o vatri”. Studia ethnologica Croatica, vol. 23:353-355. https://hrcak.srce.hr/74754

POTKONJAK, Sanja. 2011. "Marijana Hameršak i Suzana Marjanić, ur. Folkloristička čitanka”. Studia ethnologica Croatica, vol. 23:371374. https://hrcak.srce.hr/74761

RAJKOVIĆ IVETA, Marijeta. 2011. "Karmen Medica, Goran Lukič i Milan Bufon, ur.: Migranti v Sloveniji - med integracijo in alienacijo". Studia ethnologica Croatica, vol. 23:377-379. https:// hrcak.srce.hr/74763

\section{Svezak 24 (2012)}

\section{Izvorni znanstveni članak}

GRGURINOVIĆ, Ivona. 2012. "Antropologija i putovanje: praksa i tekst" / "Anthropology and Travel: Practice and Text (Translation)". Studia ethnologica Croatica, vol. 24:31-60. https://hrcak.srce.hr/93965

KOZOROG, Miha. 2012. "Primjer slučajnog turizma: društveni i prostorni čimbenici festivalskog turizma u Tolminu u Sloveniji” = "Social and Spatial Generators of Festival Tourism in Tolmin, Slovenia" [Summary]. Studia ethnologica Croatica, vol. 24:87106. https://hrcak.srce.hr/93967

OBAD, Orlanda. 2012. "Prednosti podređenosti, slabosti emancipacije? Kako hrvatski poljoprivredni poduzetnici doživljavaju EU" = "Advantages of Subordination, Weaknesses of Emancipation? How Croatian Agricultural Entrepreneurs Perceive the EU" [Summary]. Studia ethnologica Croatica, vol. 24:147-166. https://hrcak.srce. $\mathrm{hr} / 93970$

SLAVEC GRADIŠNIK, Ingrid. 2012. "Ethnologia Europaea in Croatia and Slovenia: Branimir Bratanić (1910-1986) and Vilko Novak (1909-2003)" = "Ethnologia Europaea u Hrvatskoj i Sloveniji: Branimir Bratanić (1910. - 1986.) i Vilko Novak (1909. 2003.)" [Sažetak]. Studia ethnologica Croatica, vol. 24:7-30. https://hrcak. srce.hr/93964 
VUKELIĆ, Deniver. 2012. "Problemi identifikacije i identiteta u hrvatskih “šamana' s kraja 20. i početka 21. stoljeća” = "Problems of Identification and Identity of Croatian 'Shamans' from the End of the 20th and the Beginning of the 21st Century" [Summary]. Studia ethnologica Croatica, vol. 24:167-194. https://hrcak.srce.hr/93971

\section{Prethodno priopćenje}

KRAVANJA, Boštjan. 2012. "On Social Inequality in Tourism Development and Tourist Marketing of Postcolonial Sri Lanka" = "O socijalnoj nejednakosti u razvoju turizma i turističkom marketingu u postkolonijalnoj Šri Lanki” [Sažetak]. Studia ethnologica Croatica, vol. 24:107-129. https://hrcak.srce.hr/93968

SIMONIČ, Peter. 2012. "Heritage, Development and Nature: The Purpose of Anthropology of Protected Areas" = "Baština, razvoj i priroda: svrha antropologije zaštićenih područja" [Sažetak]. Studia ethnologica Croatica, vol. 24:131-146. https://hrcak.srce.hr/93969

ŠEŠO, Luka. 2012. "Which Woman is a Witch? The Stereotypic Notions about Witches in Croatian Traditional Beliefs" = "Koja je žena vještica? Stereotipne predodžbe o vješticama u hrvatskim tradicijskim vjerovanjima" [Sažetak]. Studia ethnologica Croatica, vol. 24:195207. https://hrcak.srce.hr/93972

\section{Pregledni rad}

BATINA, Klementina. 2012. "Postmoderni putnik: prilog razumijevanju suvremene kulture putovanja" = "Postmodern Traveler: A Contribution to Understanding Contemporary Travel Culture" [Summary]. Studia ethnologica Croatica, vol. 24:6185. https://hrcak.srce.hr/93966

\section{Recenzija, Prikaz}

ČERNELIĆ, Milana. 2012. "Godišnjak za znanstvena istraživanja (br. 1 br. 3.)". Studia ethnologica Croatica, vol. 24:232-235. https://hrcak. srce.hr/93982 
GRBIĆ, Jadranka. 2012. “Andrea Matošević: Pod zemljom. Antropologija rudarenja na Labinštini u XX. stoljeću”. Studia ethnologica Croatica, vol. 24:214-217. https://hrcak.srce.hr/93975

HAMERŠAK, Marijana. 2012. "Uršula Lipovec Čebron i Jelka Zorn, ur: Zgodbe izbrisanih prebivalcev". Studia ethnologica Croatica, vol. 24:224-226. https://hrcak.srce.hr/93979

KOMAR, Tibor. 2012. "Alan Barnard: Povijest i teorija antropologije". Studia ethnologica Croatica, vol. 24:211-212. https://hrcak.srce. $\mathrm{hr} / 93973$

OROZ, Tomislav. 2012. "History as a Foreign Country: Historical Imagery in the Southeastern Europe. Druga međunarodna znanstvena konferencija". Studia ethnologica Croatica, vol. 24:236-237. https://hrcak.srce.hr/93983

PETROVIĆ, Duško. 2012. "Petra Somek: Tradicijsko graditeljstvo u Podravini: Pregled s karakterističnim primjerima". Studia ethnologica Croatica, vol. 24:219-221. https://hrcak.srce.hr/93977

PETROVIĆ, Duško. 2012. "Tea Škokić i Ines Prica, ur: Horror - Porno - Ennui (kulturne prakse postsocijalizma)". Studia ethnologica Croatica, vol. 24:229-232. https://hrcak.srce.hr/93981

POTKONJAK, Sanja. 2012. "Ivana Radačić i Jelka Vince Pallua, ur.: Ljudska prava žena. Razvoj na međunarodnoj i nacionalnoj razini 30 godina nakon usvajanja Konvencije UN-a o uklanjanju svih oblika diskriminacije žena". Studia ethnologica Croatica, vol. 24:226-229. https://hrcak.srce.hr/93980

POTKONJAK, Sanja. 2012. "Marijana Hameršak: Pričalice. O povijesti djetinjstva i bajke". Studia ethnologica Croatica, vol. 24:213214. https://hrcak.srce.hr/93974

PU゚TOVÁ, Barbora. 2012. “Anne-Marie Bouttiaux \& Anna Seiderer, eds.: Fetish Modernity”. Studia ethnologica Croatica, vol. 24:221223. https://hrcak.srce.hr/93978

UREM, Sandra. 2012. "Body and Awareness. The Discourse between Anthropology, Literature and the Arts". Studia ethnologica Croatica, vol. 24:238-240. https://hrcak.srce.hr/93984 
ZEBEC, Tvrtko. 2012. "Iva Niemčić: Lastovski poklad: plesno-etnološka studija”. Studia ethnologica Croatica, vol. 24:218-219. https://hrcak. srce.hr/93976

\section{Svezak 25 (2013)}

\section{Izvorni znanstveni članak}

ČARGONJA, Hrvoje. 2013. "Bodies and Worlds Alive: an Outline of Phenomenology in Anthropology" = "Živaijela i svjetovi: pregled fenomenologije u antropologiji" [Sažetak]. Studia ethnologica Croatica, vol. 25:19-60. https://hrcak.srce.hr/112103

GRGURINOVIĆ, Ivona. 2013. "Putnici i statisti: o politici (akademske) mobilnosti" / "The Travellers and the Still: on the Politics of (Academic) Mobility (Translation)". Studia ethnologica Croatica, vol. 25:129-158. https://hrcak.srce.hr/112105

KATARINČIĆ, Ivana. 2013. "Rod u predodžbama: stereotipizacija u klasičnom baletu" = "Gender in Perception: Stereotypes in Classical Ballet” [Summary]. Studia ethnologica Croatica, vol. 25:283-304. https://hrcak.srce.hr/112116

LUNAČEK, Sarah. 2013. "Tuareg Travelling to Europe: Particularities and Continuities" = "Tuarezi putuju u Europu: osebujnosti i kontinuiteti" [Sažetak]. Studia ethnologica Croatica, vol. 25:159182. https://hrcak.srce.hr/112106

RUBIĆ, Tihana. 2013. "Nezaposlenost i neformalna ekonomija u Hrvatskoj: analiza diskursa" / "Unemployment and Informal Economy in Croatia: Discourse Analysis (Translation)". Studia ethnologica Croatica, vol. 25:61-128. https://hrcak.srce.hr/112104

SELBERG, Torunn i Nevena ŠKRBIĆ ALEMPIJEVIĆ. 2013. "Turning Fiction into Reality: the Making of Two Places within Literary Geography" = "Kako fikciju pretvoriti u stvarnost: stvaranje dvaju mjesta u književnoj geografiji” [Sažetak]. Studia ethnologica Croatica, vol. 25:183-206. https://hrcak.srce.hr/112108

VINCE PALLUA, Jelka. 2013. “'Baba gljive brala' - međimurska svadbena dramska igra kao izvor i put do svetosti praslavenskoga 
obreda" = "Baba Went Picking Mushrooms' - a Wedding Dramatic Play from Međimurje as a Source and a Path to the Sacredness of Protoslavic Rituals" [Summary]. Studia ethnologica Croatica, vol. 25:231-252. https://hrcak.srce.hr/112111

\section{Prethodno priopćenje}

DRUŽETIĆ, Ivana. 2013. "Francuska zabrana muslimanske burke i njezini odjeci u hrvatskim medijima" = "France's Muslim Burqua Ban and its Reflections in the Croatian Media" [Summary]. Studia ethnologica Croatica, vol. 25:207-230. https://hrcak.srce.hr/112109

LAKIĆ PARAĆ, Iva. 2013. "Sinkretičke religijske prakse na području Yamagate (Japan)" = "Syncretic Religious Practices in Case of Yamagata, Japan" [Summary]. Studia ethnologica Croatica, vol. 25:253-281. https://hrcak.srce.hr/112113

\section{Recenzija, Prikaz}

CERIBAŠIĆ, Naila. 2013. "Petra Kelemen i Nevena Škrbić Alempijević: Grad kakav bi trebao biti. Etnološki i kulturnoantropološki osvrti na festivale. Zagreb: Naklada Jesenski i Turk, 2012., 456 str.”. Studia ethnologica Croatica, vol. 25:335-338. https://hrcak.srce.hr/112281

CZERNY, Sarah. 2013. "Suzana Marjanić and Antonija Zaradija Kiš, eds.: Literary Animals. Cultural Bestiary, Part II. Zagreb: Institut za etnologiju i folkloristiku and Hrvatska sveučilišna naklada, 2012., pp. 1143". Studia ethnologica Croatica, vol. 25:351-353. https:// hrcak. srce.hr/112287

GULIN ZRNIĆ, Valentina. 2013. "Dorothee Brantz i Sonja Dümpelmann, ur.: Greening the City. Urban Landscapes in the Twentieth Century. Charlottesville: University of Virginia Press, 2011., 246 str.”. Studia ethnologica Croatica, vol. 25:347-351. https://hrcak.srce.hr/112286

HAMERŠAK, Marijana. 2013. "Jelena Marković: Pričanja o djetinjstvu. Žiot priča u svakodnevnoj komunikaciji. Zagreb: Institut za etnologiju i folkloristiku, 2012., 367 str.”. Studia ethnologica Croatica, vol. 25:338-340. https://hrcak.srce.hr/112283 
JOLIĆ, Robert. 2013. “Fabrications on Medjugorje: on Mart Bax' Research. MART BAX, Medjugorje: Religion, Politics, and Violence in Rural Bosnia [Međugorje: religija, politika i nasilje u ruralnoj Bosni], Amsterdam: VU Uitgeverij, 1995., pp. xix+139”. Studia ethnologica Croatica, vol. 25:309-328. https://hrcak.srce.hr/112276

KOMAR, Tibor. 2013. “Ozren Biti: Nadzor nad tijelom. Vrhunski sport iz kulturološke perspektive. Zagreb: Institut za etnologiju i folkloristiku, 2012., 272 str.”. Studia ethnologica Croatica, vol. 25:332-334. https://hrcak.srce.hr/112280

MIŠETIĆ, Martina. 2013. "Romana Habartová i Markéta Holubová, ur.: Svět mužů a žen. Muž a žena ve svědectvích lidových tradic, Studie Slováckého muzea 16. Uherské Hradiště: Slovácké muzeum v Uherském Hradišti, př́ispěvková organizace, 2011., 287 str.”. Studia ethnologica Croatica, vol. 25:354-355. https://hrcak.srce. $\mathrm{hr} / 112288$

PETROVIĆ LEŠ, Tihana. 2013. "Juraj Zajonc: Premeny vlákna. Trnava: Edition Ryba, 2012., 235 str.”. Studia ethnologica Croatica, vol. 25:345-347. https://hrcak.srce.hr/112285

POTKONJAK, Sanja. 2013. "Lynette Šikić-Mićanović: Skriveni životi. Prilog antropologiji ruralnih žena. Zagreb: Institut 'Ivo Pilar', Biblioteka Centra za urbane i ruralne studije, 2012., 169 str. i Hannes Grandits: Obitelj i socijalne promjene u hrvatskim selima (18. - 20. stoljeće). Studije slučaja Bobovac i Lekenik. Zagreb: FF Press, 2012., 291 str.”. Studia ethnologica Croatica, vol. 25:341-345. https://hrcak.srce.hr/112284

RADULOVIĆ, Lidija. 2013. "Marijana Belaj: Milijuni na putu. Antropologija hodočašća i sveto tlo Međugorja. Zagreb: Naklada Jesenski i Turk, 2012., 263 str.”. Studia ethnologica Croatica, vol. 25:329-332. https://hrcak.srce.hr/112278

\section{Ostalo}

ČARGONJA, Hrvoje. 2013. "Addendum to the article 'Ambiguous Experience: A Contribution to Understanding Experience as Discourse' by Hrvoje Čargonja (Studia ethnologica Croatica, vol. 23 
(2011):283-308)”. Studia ethnologica Croatica, vol. 25:305306. https://hrcak.srce.hr/112274

MARJANIĆ, Suzana. 2013. “O pasioniranom istraživaču i prijatelju s krova svijeta. In memoriam: Tomo Vinšćak". Studia ethnologica Croatica, vol. 25:7-17. https://hrcak.srce.hr/112101

\section{Svezak 26 (2014)}

\section{Izvorni znanstveni članak}

ĐURIN, Sanja. 2014. "Konstrukcija društvenog sjećanja u muzejima regije Magallanes u Čileu" = "Constructs of Social Memory in Museums of the Magallanes Region in Chile" [Summary]. Studia ethnologica Croatica, vol. 26:73-89. https://doi.org/10.17234/SEC.26.4

LEČEK, Suzana. 2014. “'Stanovnici su protivni iz čisto sentimentalnih razloga'. Kampanja mijenjanja 'anacionalnih' imena mjesta u Savskoj banovini (1934.-36.)" = "'Residents are Opposed to the Idea Often for Sentimental Reasons' - A Campaign to Change Non-National Place Names in Savska Banovina (1934-1936)" [Summary]. Studia ethnologica Croatica, vol. 26:183-228. https://doi.org/10.17234/ SEC. 26.8

MILENKOVIĆ, Miloš. 2014. “Povratak 'dvorskoj nauci’? - Ka konsekvencijalističkom promišljanju budućnosti etnologije / sociokulturne antropologije u Republici Srbiji i Republici Hrvatskoj" = "A Return to "Courtly Science'? Towards a Consequential Consideration of the Future of Ethnology / SocioCultural Anthropology in Serbia and Croatia" [Summary]. Studia ethnologica Croatica, vol. 26:5-23. https://doi.org/10.17234/ SEC.26.1

PERIĆ KASELJ, Marina. 2014. "Dijasporske zajednice u kiberprostoru: virtualni identiteti hrvatskih etničkih zajednica u Čileu i Argentini”" = "Diaspora Communities in Cyberspace: Virtual Identities of Croatian Ethnic Communities in Chile and Argentine" [Summary]. Studia ethnologica Croatica, vol. 26:91-119. https://doi.org/10.17234/ SEC.26.5 
PETROVIĆ LEŠ, Tihana. 2014. "Uloga veza u oblikovanju nacionalnog identiteta ili kako je pečki postao narodni vez" = "The Role of Embroidery in Shaping National Identity or How Pec Embroidery Became National Embroidery" [Summary]. Studia ethnologica Croatica, vol. 26:149-182. https://doi.org/10.17234/SEC.26.7

POTKONJAK, Sanja i Tomislav PLETENAC. 2014. “'Ja, Europljanin': kulturna reprezentacija Hrvatske na putu u Europsku uniju” = “'I, a European': Cultural Representation of Croatia on the Path to the European Union" [Summary]. Studia ethnologica Croatica, vol. 26:121-147. https://doi.org/10.17234/SEC.26.6

POZNIAK, Romana i Duško PETROVIĆ. 2014. "Tražitelji azila kao prijetnja" = "Asylum Seekers as a Threat" [Summary]. Studia ethnologica Croatica, vol. 26:47-72.https://doi.org/10.17234/SEC.26.3

\section{Prethodno priopćenje}

JELASKA MARIJAN, Zdravka. 2014. "Službena imenovanja i preimenovanja ulica u Splitu 1912.-1928. godine" = "The Official Naming and Renaming of Streets in Split 19121928" [Summary]. Studia ethnologica Croatica, vol. 26:229-252. https://doi.org/10.17234/SEC.26.9

\section{Pregledni rad}

INGEBJØRG FJELL, Tove. 2014. "Challenges Presented by Research Methods and Ethics in Cultural Studies - Blurred Boundaries between Public and Private" = "Izazovi postavljeni istraživačkim metodama i etikom u kulturalnim studijima - zamagljene granice između javnog i privatnog" [Sažetak]. Studia ethnologica Croatica, vol. 26:25-45. https://doi.org/10.17234/SEC.26.2

\section{Recenzija, Prikaz}

BELAJ, Melanija. 2014. "Ivona Orlić: Istra kroz tri generacije. Između svakodnevne konstrukcije identiteta i turističkog proizvoda". Studia ethnologica Croatica, vol. 26:263-266. https://hrcak.srce.hr/133400 
GRBIĆ, Jadranka. 2014. "Lidija Nikočević: Zvončari i njihovi odjeci”. Studia ethnologica Croatica, vol. 26:259-263. https://hrcak.srce. $\mathrm{hr} / 133399$

JAMBREŠIĆ KIRIN, Renata. 2014. "Andrea Pisac: Hakirana Kiti: ljubavno-znanstveni roman". Studia ethnologica Croatica, vol. 26:266-269. https://hrcak.srce.hr/133401

PERIĆ KASELJ, Marina. 2014. "Jasna Čapo, Caroline Hornstein Tomić i Katica Jurčević, ur.: Didov san: Transgranična iskustva hrvatskih iseljenika". Studia ethnologica Croatica, vol. 26:272-275. https:// hrcak.srce.hr/133403

ŠKILJAN, Filip. 2014. "Marijeta Rajković Iveta: Česi u Jazveniku". Studia ethnologica Croatica, vol. 26:270-272. https://hrcak.srce.hr/133402 ŠKOKIĆ, Tea. 2014. “Anita Sujoldžić, ur.: Antropološko nazivlje”. Studia ethnologica Croatica, vol. 26:275-277. https://hrcak.srce.hr/133404

VOJAK, Danijel. 2014. "Ian Hancock: We are the Romani People - Ame sam e Rromane džene". Studia ethnologica Croatica, vol. 26:255259. https://hrcak.srce.hr/133398

\section{Svezak 27 (2015)}

\section{Izvorni znanstveni članak}

GRBIĆ JAKOPOVIĆ, Jadranka. 2015. "Bugarski vrtlari: refleksije o povijesti urbanog vrtlarenja u Hrvatskoj" = "Bulgarian Gardeners: Reflections on the History of Urban Gardening in Croatia" [Summary]. Studia ethnologica Croatica, vol. 27:71-104. https://doi. org/10.17234/SEC.27.2

KATARINČIĆ, Ivana. 2015. "World dance: (novi) eufemizam u plesnoj terminologiji?" / "World Dance: a (New) Euphemism in Dance Terminology? (Translation)". Studia ethnologica Croatica, vol. 27:327-343. https://doi.org/10.17234/SEC.27.8

KOMAR, Tibor. 2015. "Identitet i/kroz sport: antropološki pristup istraživanju dijaspore" = "Identity and/through Sports: Anthropological Approach to the Research of Diaspora" [Summary]. Studia ethnologica Croatica, vol. 27:393-414. https://doi.org/10.17234/SEC.27.10 
PERIĆ KASELJ, Marina, et al. 2015. “Događaj i etnička situacija: promjene identiteta nacionalnih manjinskih zajednica u Republici Hrvatskoj" / "Event and Ethnic Situation: Changes to the Identity of National Minority Communities in the Republic of Croatia (Translation)". Studia ethnologica Croatica, vol. 27:7-70. https:// doi. org/10.17234/SEC.27.1

OROZ, Tomislav i Nevena ŠKRBIĆ ALEMPIJEVIĆ. 2015. "Dva lica spomenika: politike i prakse korištenja Spomenika Seljačkoj buni i Matiji Gupcu u Gornjoj Stubici" / "Two Faces of the Monument: Politics and Practices in the Usages of the Monument to the Peasant Revolt and Matija Gubec in Gornja Stubica (Translation)". Studia ethnologica Croatica, vol. 27:131-187. https://doi.org/10.17234/ SEC.27.4

TKALČIĆ, Marina. 2015. "Vile i vilinska pedagogija u novopoganskim duhovnostima u Hrvatskoj" / "Faeries and Faery Pedagogy in Neopagan Spiritualities in Croatia (Translation)". Studia ethnologica Croatica, vol. 27:189-246. https://doi.org/10.17234/SEC.27.5

UREM, Sandra. 2015. "Specifičnost disciplinarnih i institucionalnih pristupa etnografskom filmu - Milovan Gavazzi i Andrija Štampar" / "Specific Features of Disciplinary and Institutional Approaches to Ethnographic Film - Milovan Gavazzi and Andrija Štampar (Translation)". [Studia ethnologica Croatica, vol. 27:247-305. https://doi.org/10.17234/SEC.27.6

UZELAC, Kristina, et al. 2015. “"That was a joke, you should laugh!' Tour Guides and the Performance of History in Budapest, Hungary" = “'Ovo je trebalo biti smiješno - zašto se ne smijete!' - izvođenje povijesti i turističke šetnje u Budimpešti” [Sažetak]. Studia ethnologica Croatica, vol. 27:307-326. https://doi.org/10.17234/ SEC.27.7

\section{Prethodno priopćenje}

FJELL, Tove Ingebjørg. 2015. "Discrimination of Men? Narratives on Traditional Understandings of Gender" = "Diskriminacija muškaraca? Priče o tradicionalnim razumijevanjima roda" [Sažetak]. Studia 
ethnologica Croatica, vol. 27:363-391. https://

doi.org/10.17234/SEC.27.9

KAPETANOVIĆ, Mišo. 2015. "Post-Socialist Landscape: a Castle by the Road" = "Postsocijalistički krajolik: dvorac pokraj ceste" [Sažetak]. Studia ethnologica Croatica, vol. 27:449-478. https://doi. org/10.17234/SEC.27.12

PERINIĆ LEWIS, Ana i Maja ADŽIJA. 2015. "Globalna i lokalna plaža na primjeru dubrovačkih gradskih plaža i plažnih kultura" = "The Global and Local Beach: Dubrovnik Town Beach and Beach Cultures as Case Study" [Summary]. Studia ethnologica Croatica, vol. 27:415-447. https://doi.org/10.17234/SEC.27.11

\section{Pregledni rad}

ČAPO ŽMEGAČ, Jasna. 2015. "Prijepori oko naslijeđa prošlosti i memorija u Hrvatskoj: znanstveno-popularna publikacija pod pritiskom ideologija" = "Conflicts over Past Heritage and Memory in Croatia: an Academic-Lay Publication in the Grips of Ideology" [Summary]. Studia ethnologica Croatica, vol. 27:105129. https://doi.org/10.17234/SEC.27.3

\section{Recenzija, Prikaz}

BELAJ, Melanija. 2015. “Tihana Rubić i Valentina Gulin Zrnić, ur.: Vrtovi našega grada. Studije i zapisi o praksama urbanog vrtlarenja. Zagreb: Institut za etnologiju i folkloristiku, 2015., 232 str.”. Studia ethnologica Croatica, vol. 27:510-513. https://hrcak.srce. $\mathrm{hr} / 150881$

DRONJIĆ, Matija. 2015. “Drago Roksandić, Marijeta Rajković Iveta, Tihana Rubić, ur.: Kula Jankovića. Spomenik kulture - pokretač održivog razvoja Ravnih kotara Baština, interkulturalizam i revitalizacija. Zagreb: Sveučilište u Zagrebu, Filozofski fakultet, Centar za komparativnohistorijske i interkulturne studije - Plejada d. o. o., 2014., 174 str.”. Studia ethnologica Croatica, vol. 27:507-510. https://hrcak.srce.hr/150880 
GRBIĆ JAKOPOVIĆ, Jadranka. 2015. "Milana Černelić, ur.: Tradicijska baština i etnokulturni identitet podunavskih Hrvata Bunjevaca. Zagreb: Filozofski fakultet Sveučilišta u Zagrebu, Odsjek za etnologiju i kulturnu antropologiju, FF press - Subotica: Zavod za kulturu vojvođanskih Hrvata, 2014., 523 str.”. Studia ethnologica Croatica, vol. 27:500-502. https://hrcak.srce.hr/150877

GRBIĆ JAKOPOVIĆ, Jadranka. 2015. “Jelka Vince Pallua: Zagonetka virdžine. Etnološka i kulturnoantropološka studija. Zagreb: Institut za društvena istraživanja Ivo Pilar, Biblioteka Studije 18, 2014., 310 str.". Studia ethnologica Croatica, vol. 27:497-500. https://hrcak. srce.hr/150876

GULIN ZRNIĆ, Valentina. 2015. “Sanja Potkonjak: Teren za etnologe početnike. Zagreb: Hrvatsko etnološko društvo, HED biblioteka - Filozofski fakultet Sveučilišta u Zagrebu, FF press, Odsjek za etnologiju i kulturnu antropologiju, 2014., 103 str. (tiskano i elektroničko izdanje)". Studia ethnologica Croatica, vol. 27:494497. https://hrcak.srce.hr/150874

MARJANIĆ, Suzana. 2015. "Boris Perić i Tomislav Pletenac: Zemlja iza šume. Vampirski mit u književnosti i na filmu. Zagreb: TIM press, 2015., 190 str.". Studia ethnologica Croatica, vol. 27:487-490. https://hrcak.srce.hr/150872

POTKONJAK, Sanja. 2015. “Iva Pleše: Pismo, poruka, mejl: etnografija korespondencije. Zagreb: Institut za etnologiju i folkloristiku, 2014., 277 str.". Studia ethnologica Croatica, vol. 27:491-494. https://hrcak.srce.hr/150873

PRICA, Ines. 2015. "Suzana Marjanić: Kronotop hrvatskoga performansa: od Travelera do danas. Zagreb: Institut za etnologiju i folkloristiku - Udruga Bijeli val - Školska knjiga, 2014., 1998 str.”. Studia ethnologica Croatica, vol. 27:484-486. https://hrcak.srce.hr/150871

ŠANTEK, Goran Pavel. 2015. "Mario Katić, Tomislav Klarin, Mike McDonald, ur.: Pilgrimage and Sacred Places in Southeast Europe: History, Religious Tourism and Contemporary Trends. Zürich Berlin: LIT Verlag, 2014., 232 str.”. Studia ethnologica Croatica, vol. 27:504-507. https://hrcak.srce.hr/150879 
ŠANTEK, Goran Pavel. 2015. "Milana Černelić, Jadranka Grbić Jakopović, Tihana Rubić, Marijeta Rajković Iveta, Matija Dronjić, Mihovil Gotal, ur.: Bunjevci u vremenskom i prostornom kontekstu. Zagreb: Filozofski fakultet Sveučilišta u Zagrebu, Odsjek za etnologiju i kulturnu antropologiju, FF press - Subotica: Zavod za kulturu vojvođanskih Hrvata, 2014., 686 str.”. Studia ethnologica Croatica, vol. 27:502-504. https://hrcak.srce.hr/150878

ŠKILJAN, Filip. 2015. "Jadranka Grbić Jakopović: Multipliciranje zavičaja i domovina. Hrvatska dijaspora: kronologija, dijaspora i identitet. Zagreb: Filozofski fakultet Sveučilišta u Zagrebu, 2014., 200 str.". Studia ethnologica Croatica, vol. 27:481-484. https:// hrcak.srce.hr/150870

\section{Svezak 28 (2016)}

\section{Izvorni znanstveni članak}

FAKIN BAJEC, Jasna. 2016. "Cultural Heritage and the Role of Voluntary Associations in the Process of Achieving Sustainable Development in Rural Communities" = "Kulturna baština i uloga volonterskih udruga $\mathrm{u}$ procesima postizanja održivog razvoja u ruralnim zajednicama" [Sažetak]. Studia ethnologica Croatica, vol. 28:2145. https://doi. org/10.17234/SEC.28.2

JURKOVIĆ, Rahela i Marijeta RAJKOVIĆ IVETA. 2016. “"Okus doma': integracija azilanata protkana transnacionalnim procesima $\mathrm{i}$ promicanjem kulinarskih tradicija" / "Taste of Home': Integration of Asylees Intertwined with Transnational Processes and the Promotion of Culinary Traditions (Translation)". Studia ethnologica Croatica, vol. 28:147-211. https://doi.org/10.17234/SEC.28.7

MARJANIĆ, Suzana. 2016. "Krležin razgovor o Brest-Litovsku (1918.) kao apologija Oktobra ili politike prijateljstva" / "Krleža's Talk about Brest-Litovsk (1918) as an Apologia for October Revolution or the Politics of Friendship (Translation)". Studia ethnologica Croatica, vol. 28:267-314. https://doi.org/10.17234/SEC.28.10

PERIĆ KASELJ, Marina. 2016. "Kako smo postali Jugoslaveni: o etničkim/nacionalnim identitetima Hrvata u Čileu i Argentini za 
vrijeme Prvoga svjetskog rata" = "How We Became Yugoslavs: On Ethnic/National Identities of Croats in Chile and Argentina During WWI” [Summary]. Studia ethnologica Croatica, vol. 28:233-265. https://doi.org/10.17234/SEC.28.9

PETERNEL, Lana i Filip ŠKILJAN. 2016. "Etniciteti, nacije i granice na Kordunu: primjer bošnjačke nacionalne manjine" = "Ethnicities, Nations and Boundaries in Kordun: An Example of Bosniak Ethnic Minority" [Summary]. Studia ethnologica Croatica, vol. 28:213232. https://doi.org/10.17234/SEC.28.8

\section{Prethodno priopćenje}

HERMAN KAURIĆ, Vijoleta. 2016. "Doživljaj Prvoga svjetskog rata Mije Čipora ili koliko smo određeni krajolikom odrastanja" = "Mijo Čipor's Experience of WWI or How We are Determined by Our Childhood Landscape" [Summary]. Studia ethnologica Croatica, vol. 28:363-381. https://doi.org/10.17234/SEC.28.13

LOSARDO, Martina. 2016. "'New Ways of Living, as Old as the World”: Best Practices and Sustainability in the Example of the Italian Ecovillage Network" = "Novi načini življenja, stari kao i svijet': dobra praksa i održivost na primjeru Talijanske mreže ekosela" [Sažetak]. Studia ethnologica Croatica, vol. 28:47-70. https://doi. org/10.17234/SEC.28.3

LUKEC, Katarina. 2016. “'Za jedne on je heroj, a drugima je zločinac' Gavrilo Princip u popularnoj kulturi 100 godina nakon Sarajevskog atentata" = "For Some He is a Hero, for Others a Criminal" - Gavrilo Princip in Popular Culture a Hundred Years after the Assassination in Sarajevo" [Summary]. Studia ethnologica Croatica, vol. 28:315337. https://doi.org/10.17234/SEC.28.11

VLADISLAVIĆ, Ante Tonči. 2016. "Veliki rat - velike promjene: čitanje promjena slike vojne uniforme" = "Great War - Great Changes: Reading the Changing Image of the Military Uniform" [Summary]. Studia ethnologica Croatica, vol. 28:339362. https://doi.org/10.17234/SEC.28.12 


\section{Pregledni rad}

KARLSONE, Anete. 2016. "Traditional Craft Skills in the Contemporary Latvian Rural Environment" = "Vještine tradicijskih obrta u suvremenoj latvijskoj ruralnoj sredini” [Sažetak]. Studia ethnologica Croatica, vol. 28:71-90. https://doi.org/10.17234/SEC.28.4

LEDINEK LOZEJ, Špela. 2016. "Dairying in the Mountain Pastures in the Julian Alps: Heritages, Utopias and Realities" = "Mljekarstvo na planinskim pašnjacima Julijskih Alpa: tradicije, utopije i realnosti” [Sažetak]. Studia ethnologica Croatica, vol. 28:91-111. https://doi. org/10.17234/SEC.28.5

\section{Stručni rad}

ŽIVAKOVIĆ-KERŽE, Zlata i Darko MRKONJIĆ. 2016. "Kopački Rit Traditional Fishing as Cultural Tourism Potential and Environmental Protection Measure" = "Tradicijski ribolov u Kopačkom ritu kao kulturno-turistički potencijal i mjera zaštite okoliša" [Sažetak]. Studia ethnologica Croatica, vol. 28:113-145. https:// doi.org/10.17234/SEC.28.6

\section{Recenzija, Prikaz}

DIMITROVSKA, Elena. 2016. "Wladimir Fischer-Nebmaier, Matthew P. Berg, Anastasia Christou, ur.: Narrating the City. History, Space and the Everyday". Studia ethnologica Croatica, vol. 28:395-399. https://hrcak.srce.hr/171898

GLAVOČIĆ, Tia. 2016. “Kazivač - časopis za etnološke i kulturnoantropološke teme, god. 1, br. 1, 2015.”. Studia ethnologica Croatica, vol. 28:407-407. https://hrcak.srce.hr/171901

GOVIĆ, Vana. 2016. “Znanstveni skup Mune Maksu Pelozi u povodu stogodišnjice rođenja svećenika i povjesničara dr. sc. Maksa Peloze (1915.-1989.)". Studia ethnologica Croatica, vol. 28:399-403. https://hrcak.srce.hr/171899

GRABAR, Ena. 2016. “14th International 'Border Crossings' Student Conference: Ethnographies of (Un)certainty, (In)equality and 
Hope(lessness): Challenges and Possibilities for Anthropology Today". Studia ethnologica Croatica, vol. 28:408-409. https://hrcak. srce.hr/171903

HERŠAK, Emil. 2016. "Laura Šakaja: Uvod u kulturnu geografiju”. Studia ethnologica Croatica, vol. 28:385-389. https://hrcak.srce.hr/171893

KALČIĆ, Martina. 2016. "Mirjam Milharčič Hladnik, ur.: From Slovenia to Egypt: Aleksandrinke's Trans-Mediterranean Domestic Workers' Migration and National Imagination". Studia ethnologica Croatica, vol. 28:403-406. https://hrcak.srce.hr/171900

RAJKOVIĆ IVETA, Marijeta. 2016. "Dragutin Babić: Nacionalne manjine u Hrvatskoj. Sociološka perspektiva”. Studia ethnologica Croatica, vol. 28:393-395. https://hrcak.srce.hr/171896

RATKOVČIĆ, Rosana. 2016. “Josip Zanki, Marijana Paula Ferenčić, Nevena Škrbić Alempijević, Sanja Potkonjak, Marijana Belaj, ur.: Od državne umjetnosti do kreativnih industrija / Transformacija rodnih, političkih i religijskih narativa". Studia ethnologica Croatica, vol. 28:390-393. https://hrcak.srce.hr/171895

\section{Ostalo}

LONČAR, Sanja i Saša POLJAK ISTENIČ. 2016. "Local (Traditional) Knowledge as the Key for Sustainable Rural Development: Utopia or Reality? (Introduction to thematic section)". Studia ethnologica Croatica, vol. 28: 11-20. https://doi.org/10.17234/SEC.28.1

\section{Svezak 29 (2017)}

\section{Izvorni znanstveni članak}

AUMILLER, Rachel. 2017. “Antigone's stance amongst Slovenia’s undead" = "Položaj Antigone među slovenskim besmrtnicima" [Sažetak]. Studia ethnologica Croatica, vol. 29:1943. https://doi. org/10.17234/SEC.29.1

ČAPO, Jasna i Petra KELEMEN. 2017. "Zagreb očima međunarodnih migranata: značenja, potencijali i (re)skaliranja grada" = "Zagreb through the eyes of international migrants: Meanings, potentials and 
(re)scaling of the city" [Summary]. Studia ethnologica Croatica, vol. 29:251-277. https://doi.org/10.17234/SEC.29.9

ĐURIN, Sanja. 2017. “O poststrukturalističkoj teoriji diskursa krozraspravu o uvođenju pojma 'brak' u hrvatski Ustav" = "Poststructuralist discourse theory through discussion on the introduction of the concept of 'marriage' in the Croatian Constitution" [Summary]. Studia ethnologica Croatica, vol. 29:331-356. https://doi.org/10.17234/ SEC.29.12

HROBAT VIRLOGET, Katja i Neža ČEBRON LIPOVEC. 2017. “Heroes we love? Monuments to the National liberation movement in Istria between memories, care, and collective silence" = "Heroji koje volimo? Spomenici Narodnooslobodilačkom pokretu u Istri, između sjećanja, brige i kolektivne tišine" [Sažetak]. Studia ethnologica Croatica, vol. 29:45-71. https://doi.org/10.17234/SEC.29.2

ILIĆ, Kristina i Nevena ŠKRBIĆ ALEMPIJEVIĆ. 2017. "Cultures of memory, landscapes of forgetting: The case study of the Partisan memorial cemetery in Mostar" = "Kulture sjećanja, krajolici zaborava: primjer Partizanskog groblja u Mostaru" [Sažetak]. Studia ethnologica Croatica, vol. 29:73-101. https:// doi.org/10.17234/SEC.29.3

JANEV, Goran. 2017. "Burdensome past: Challenging the socialist heritage in Macedonia" = "Tegobna prošlost: propitujući socijalističko naslijeđe u Makedoniji” [Sažetak]. Studia ethnologica Croatica, vol. 29:149-170. https://doi.org/10.17234/SEC.29.8

KODRA, Romeo. 2017. "Architectural monumentalism in transitional Albania" = "Monumentalizam u arhitekturi tranzicijske Albanije" [Sažetak] = "Monumentalizmi arkitekturor nëShqipëmëe tranzicionit" [Përmbledhje]. Studia ethnologica Croatica, vol. 29:193-224. https://doi.org/10.17234/SEC.29.6

MOLEK, Nadia. 2017. "Avsenik in Buenos Aires: Transnational identification processes through polka performances among the descendants of Slovenian political exiles in Argentina" = "Avsenik u Buenos Airesu: procesi transnacionalne identifikacije kroz izvođenje polke među potomcima slovenskih političkih emigranata u Argentini”" 
[Sažetak] $=$ "Avsenik v Buenos Airesu: Procesi transnacionalne identifikacije skozi polke med potomci slovenskih političnih izgnancev v Argentini" [Povzetek] = "Avsenik en Buenos Aires: Procesos de identificación transnacional a travs de la polca entre los descendientes de los exiliados políticos Eslovenos en Argentina" [Abstracto]. Studia ethnologica Croatica, vol. 29:357384. https://doi.org/10.17234/SEC.29.13

RAJKOVIĆ IVETA, Marijeta i Rina GECI. 2017. "Albanski zlatari i pekari s Kosova u Zagrebu: Migracije i etničko poduzetništvo" = "Artart dhe furrtart Shqiptarnga Kosova n Zagreb: Migrimet dhe sipërmarrja etnike" [Përmbledhje]. Studia ethnologica Croatica, vol. 29:279-304. https://doi.org/10.17234/SEC.29.10

RAJKOVIĆ IVETA, Marijeta i Rina GECI. 2017. "Kosovar Albanian goldsmiths and bakers in Zagreb: Migration and ethnic enterpreneurship (Translation)". Studia ethnologica Croatica, vol. 29:305-330. https://doi.org/10.17234/SEC.29.11

VASILEVA, Aneta i Emilia KALEVA. 2017. "Recharging socialism: Bulgarian socialist monuments in the 21 st century" = "Oživljavanje socijalizma: bugarski socijalistički spomenici u 21. stoljeću" [Sažetak]. Studia ethnologica Croatica, vol. 29:171-192. https://doi. org/10.17234/SEC.29.5

\section{Prethodno priopćenje}

HATHERLEY, Owen. 2017. "Our monuments to glorious defeat: Socialist memorial art in Britain" = "Naši spomenici slavnom porazu: socijalistički spomenici u Velikoj Britaniji" [Sažetak]. Studia ethnologica Croatica, vol. 29:225-248. https:// doi.org/10.17234/SEC.29.7

RAKITA, Milan. 2017. "Modernization discourse and its discontents" = "Nelagodnost u diskursu modernizacije" [Sažetak]. Studia ethnologica Croatica, vol. 29:103-148. https://doi.org/10.17234/ SEC.29.4 


\section{Pregledni rad}

VOJAK, Danijel. 2017. "Počeci hrvatske romologije: od Filipa Ivana Vezdina do Franje Fanceva" = "The beginnings of Croatian Romology: From Filip Ivan Vezdin to Franjo Fancev" [Summary] = "Dm kapu a lu hrvatski romologiji: Dăla Filip Ivan Vezdin pînla Franjo Francev" [Skurtă]= "E širda e Hrvatskere Romologiakere: E Filip Ivan Vezdinestar dži Franjo Fancev" [Abstrakto]. Studia ethnologica Croatica, vol. 29:385-406. https://doi.org/10.17234/SEC.29.14

\section{Recenzija, Prikaz}

ČERNELIĆ, Milana. 2017. "Godišnjak za znanstvena istraživanja, br. 4 - br. 8, Subotica: Zavod za kulturu vojvođanskih Hrvata, 2012. 2016.”. Studia ethnologica Croatica, vol. 29:599-605. https://hrcak. srce.hr/191712

DREMEL, Anita. 2017. "Miha Kozorog i Rajko Muršič, ur.: Sounds of Attraction: Yugoslav and Post-Yugoslav Popular Music, Ljubljana, Znanstvena založba Filozofske fakultete Univerze v Ljubljani, Zbirka Zupaničeva knjižnica (Ljubljana University Press), 2017., 232 str.”. Studia ethnologica Croatica, vol. 29:613-618. https://hrcak.srce. $\mathrm{hr} / 191712$

FERENČIĆ, Marijana Paula. 2017. "Valentina Gulin Zrnić, Nevena Škrbić Alempijević, Josip Zanki, ur.: Mjesto izvedbe i stvaranje grada, Zagreb: Hrvatsko društvo likovnih umjetnika i Institut za etnologiju i folkloristiku, 2016., 204 str.”. Studia ethnologica Croatica, vol. 29:624-627. https://hrcak.srce.hr/191712

GULIN ZRNIĆ, Valentina. 2017. "Mirna Tkalčić Simetić: Hrelić antropologija prijepornog mjesta, Zagreb: Hrvatsko etnološko društvo, hed biblioteka, 2016., 112 str.". Studia ethnologica Croatica, vol. 29:618-621. https://hrcak.srce.hr/191712

KRIZMANIĆ, Matija. 2017. "Igor Duda: Danas kada postajem pionir. Djetinjstvo i ideologija jugoslavenskog socijalizma, Zagreb - Pula: Srednja Europa i Sveučilište Jurja Dobrile u Puli, 2015., 276 str.”. Studia ethnologica Croatica, vol. 29:621-624. https://hrcak.srce. $\mathrm{hr} / 191712$ 
MARJANIĆ, Suzana. 2017. "Luka Šešo, Živjeti s nadnaravnim bićima: vukodlaci, vile i vještice hrvatskih tradicijskih vjerovanja. Zagreb: Jesenski i Turk, 2016., 295 str.”. Studia ethnologica Croatica, vol. 29:605-609. https://hrcak.srce.hr/191712

MARKOVIĆ, Jelena. 2017. "Evelina Rudan: Vile s Učke: žanr, kontekst, izvedba i nadnaravna bića predaja. Zagreb: Hrvatska sveučilišna naklada - Pula: Povijesni i pomorski muzej Istre, 2016., 599 str.”. Studia ethnologica Croatica, vol. 29:609-613. https://hrcak.srce. $\mathrm{hr} / 191712$

PETROVIĆ, Duško. 2017. "Jonas Frykman i Maja Povrzanović Frykman, ur.: Sensitive Objects: Affect and Material ulture, Lund: Nordic Academic Press Checkpoint, 2016., 285 str.". Studia ethnologica Croatica, vol. 29:627-629. https://hrcak.srce.hr/191712

PLETENAC, Tomislav. 2017. "Halina Rusek, ur.: Dilemmas of old and contemporary culture in ethnographical and anthropological discourse, ieszyn - Katowice: University of Silesia in Katowice, 2011., 190 str.”. Studia ethnologica Croatica, vol. 29:630-632. https://hrcak.srce.hr/191712

\section{Ostalo}

BELAJ, Marijana. 2017. “Revizija studija etnologije i kulturne antropologije Filozofskog fakulteta Sveučilišta u Zagrebu primjenom Hrvatskoga kvalifikacijskog okvira" / "Revision of the study programme of Ethnology and Cultural Anthropology of the Faculty of Humanities and Social Sciences of the University of Zagreb by applying the Croatian Qualification Framework" [Translation]. Studia ethnologica Croatica, vol. 29:499-517. https://doi.org/10.17234/SEC.29.16

ČERNELIĆ, Milana. 2017. "Projekt 'Etnološka istraživanja Hrvata u Boki kotorskoj"” / "The 'Ethnological Research of Croats in the Bay of Kotor' Project” [Translation]. Studia ethnologica Croatica, vol. 29:537-543. https://doi.org/10.17234/SEC.29.16

ČERNELIĆ, Milana. 2017. "Projekt 'Identitet i etnogeneza primorskih Bunjevaca"" / "The "Identity and Ethnogenesis of the Littoral 
Bunjevci' Project" [Translation]. Studia ethnologica Croatica, vol. 29:518-525. https://doi.org/10.17234/SEC.29.16

ČERNELIĆ, Milana. 2017. "Projekt 'Identitet i etnokulturno oblikovanje Bunjevaca" / "The "Identity and Ethno-Cultural Formation of the Bunjevci' Project” [Translation]. Studia ethnologica Croatica, vol. 29:525-536. https://doi.org/10.17234/SEC.29.16

KELEMEN, Petra, Tihana RUBIĆ i Nevena ŠKRBIĆ ALEMPIJEVIĆ. 2017. "Projekt 'Stvaranje grada: prostor, kultura i identitet"” / "The 'City-making: Space, Culture and Identity' Project" [Translation]. Studia ethnologica Croatica, vol. 29:584595. https://doi.org/10.17234/SEC.29.16

KOMAR, Tibor. 2017. "Projekt 'Sakralna interpretacija krajobraza"” / "The 'Sacral Interpretation of Landscape' Project" [Translation]. Studia ethnologica Croatica, vol. 29:575-584. https://doi.org/10.17234/ SEC.29.16

MAJER, Ivana. 2017. "Bibliografija Odsjeka za etnologiju i kulturnu antropologiju Filozofskog fakulteta Sveučilišta u Zagrebu (2006. 2016.)". Studia ethnologica Croatica, vol. 29:411-496. https:// hrcak. srce.hr/191709

PAVEL ŠANTEK, Goran. 2017. "Projekt 'Kulturni i jezični kontekst kao odrednice za stvaranje identiteta"” / "The "Cultural and Linguistic Context as Determinants for Identity Creation' Project" [Translation]. Studia ethnologica Croatica, vol. 29:569571. https://doi.org/10.17234/SEC.29.16

PAVEL ŠANTEK, Goran. 2017. "Projekt 'Mitski krajobraz kao izvor znanja o organizaciji prostora"" / "The 'Mythical Landscape as a Source of Knowledge about the Organization of Space' Project" [Translation]. Studia ethnologica Croatica, vol. 29:566568. https://doi.org/10.17234/SEC.29.16

PAVEL ŠANTEK, Goran. 2017. "Projekt 'Priče i strukture mitskog prostora" / "The 'Stories and Structures of Mythical Space' Project" [Translation]. Studia ethnologica Croatica, vol. 29:562565. https://doi.org/10.17234/SEC.29.16 
PAVEL ŠANTEK, Goran. 2017. "Projekt 'Sport i diskriminacija. Istraživanje fenomena i mogućnosti uspješnijega društvenoga djelovanja" / "The 'Sport and Discrimination. Research of the Phenomenon and the Possibilities of a More Effective Social Activity' Project" [Translation]. Studia ethnologica Croatica, vol. 29:572574. https://doi.org/10.17234/SEC.29.16

PETROVIĆ LEŠ, Tihana. 2017. "Projekt 'Hrvatska etnografska baština u kontekstu kulturnih politika"" / "The "Croatian Ethnographic Heritage in the Context of Cultural Policy' Project" [Translation]. Studia ethnologica Croatica, vol. 29:544-545. https://doi.org/10.17234/ SEC.29.16

RAJKOVIĆ IVETA, Marijeta. 2017. "Projekt 'Centar za posjetitelje 'Kuća Velebita', Nacionalni park Sjeverni Velebit, Krasno"” / "The 'Visitor Centre 'Kuća Velebita' (Velebit House), Northern Velebit National Park, Krasno' Project”' [Translation]. Studia ethnologica Croatica, vol. 29:546-552. https://doi.org/10.17234/SEC.29.16

ROKSANDIĆ, Darko, Marijeta RAJKOVIĆ IVETA i Tihana RUBIĆ. 2017. "Projekt 'Kula Jankovića: spomenik kulture - pokretač održivog razvoja Ravnih kotara"” / "The 'Janković Castle: Historic Site, Generating Sustainable Development of the Ravni Kotari Region' Project" [Translation]. Studia ethnologica Croatica, vol. 29:553-561. https://doi.org/10.17234/SEC.29.16 